${ }^{*}$ National Bank of the Republic of Macedonia

\title{
Monetary Policy Objectives During the Crisis: An Overview of Selected Southeast European Countries
}

\begin{abstract}
The recent global crisis brought many challenges to the central bankers worldwide, including the issue of monetary policy objectives. In this view, besides price stability maintenance, a special attention by central bankers during the crisis was given to the output stabilization. This paper explores this issue on the case of a group of countries from Southeast Europe (SEE). For this purpose, rather simple analysis of the policy rate and output gap as well as output gap variability by countries have been provided, aimed at giving some initial insights of the monetary policy and output stabilization during the crisis. Our findings pointed that the central banks in the analysed SEE countries paid attention to the output stabilization, specifically during the crisis period and that was presumably enabled by controllable inflation developments.
\end{abstract}

Key words: monetary policy, central banks, interest rates, output, crisis.

JEL classification: E52, E43, O52.

\section{Introduction}

The recent global crisis brought many challenges to policymakers in different areas. Central bankers worldwide also experienced challenging times regarding the types of measures and instruments implemented, the scope of interventions, flexibility required, even regarding the policy objectives. Dynamic environment during the crisis required more frequent changes in the monetary policy setup, 
switch to variety of non-standard measures, taking care of other issues along price stability as a usual final monetary policy objective.

One of the main lessons of the global financial crisis from mid-2007 is that central banks must take care of financial stability as an important precondition for maintaining macroeconomic stability. In addition, with the further evolution of the financial crisis into an economic crisis it became more obvious that there was a need for serious efforts to support economic recovery. Developed economies faced with the situation of the zero lower bound and put in place different nonstandard measures aimed at supporting the economies. Therefore, on the edge of the crisis one could say that new horizons are open for central banks in the future.

The subject of monetary policy objectives is not a new one, but it has definitely been gaining in importance nowadays. There are many contributions in the literature pointing that, besides price stability, monetary policy must take care of output stability as well. This is something that was practiced during the crisis, albeit in different ways in developed and emerging economies. Central banks in developed economies under the zero lower bound interest rate took additional measures to support the output. Central banks in emerging economies, including the countries from Southeast Europe (SEE), were gradually reducing the interest rate and also took specific measures aimed at supporting the recovery.

This paper will try to examine the list of monetary policy objectives in view of the crisis lessons, especially the contribution of monetary policy to output stabilization on the case of group of SEE countries. The paper is organized as follows. First, there will be a literature overview, followed by some stylized facts on the monetary policy stance in the analysed SEE countries during the crisis. The next section will explore the monetary policy objectives in the analysed SEE countries, aiming to give the answer weather they also take care of the output in addition to the price stability objective. The paper ends with concluding remarks.

\section{Literature overview}

It is interesting to mention that the issue of monetary policy objectives in the literature was discussed many years before the recent global crisis. Svensson (2003) wrote that monetary policy can achieve inflation target and at best a good compromise between inflation variability and output gap variability. Central banks could improve transparency and accountability by taking care of both inflation variability and output gap variability. In addition, the author explained that cen- 
tral banks can monitor financial stability and issue warnings to concerned agents and authorities in due time in order to maintain financial stability, considering it important for the monetary policy implementation. The zero bound, liquidity traps and risks of deflation are seen as serious concerns for monetary policy and the author suggested the prudent central banks in advance to prepare contingency plans to preventing or escaping from these situations.

In his later paper, Svensson (2009) mainly focused on inflation targeting central banks, explaining that those with flexible inflation targeting strive both to stabilize inflation around the target and stabilize the real economy. In all these cases, inflation may deviate from the target if this provides a better balance between inflation and output. The author suggests that it would be desirable to evaluate the monetary policy ex ante by assessing to what extent a central bank forecast stabilizes both inflation and the real economy. According to the author, the forecast Taylor rule can be used as a tool to evaluate if the monetary policy is efficient and well-balanced by plotting mean square gaps of inflation and output gap forecasts for alternative policy rate paths. The degree of correspondence between expectations and the central bank forecast of inflation and output could be taken as a measure of credibility of the central bank's analysis and policy.

Walsh (2009) mainly focused on monetary policy and economic activity at the zero lower bound situation characteristic for developed economies during the recent crisis, considering a need for re-examination of central banks' ability to stabilize the real economy. According to the author, the central banks need to respond aggressively to negative aggregate demand shock that may push interest rate to zero, which is a kind of constraint on the ability of monetary policy to stabilize real economy. The author analysed that, during the crisis, the central banks at the zero lower bound were involved in different announcement, including the future interest rate path and that promises should be kept. Eventual presence of financial distortions will require trade-off between stability of inflation and real economic activity to ensure financial stability in the economy.

Among central banks, the American Fed has a clear dual mandate of "promoting maximum employment, stable prices and moderate long-term interest rates" (FED, 2014). Anyway, many central bankers already pointed out the messages from the last crisis about the role of the monetary policy in the economy. The financial crisis provided a costly reminder of the fact that the standard model was incomplete (Carney, 2009). Price stability is a necessary, but not sufficient condition for the stabilization of the economic activity and it must be supplemented by robust macroprudential regulatory framework (Carney, 2009). Indeed, central 
banks around the globe were trying to accommodate to the new tasks during the recent crisis.

\section{Stylized facts on monetary policy in SEE countries during the crisis}

The SEE countries analysed in this paper (Albania, Croatia, Macedonia, Serbia) displayed some common features regarding the global crisis impact. In the

Figure 1: Real GDP rates (in \%)

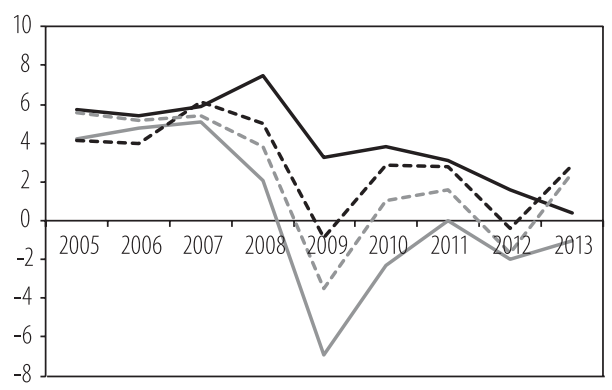

— ALBANIA C Croatia ----Macedonia ----- Serbia

Source: European Commission, National institutions.

Figure 2 Inflation (in \%)

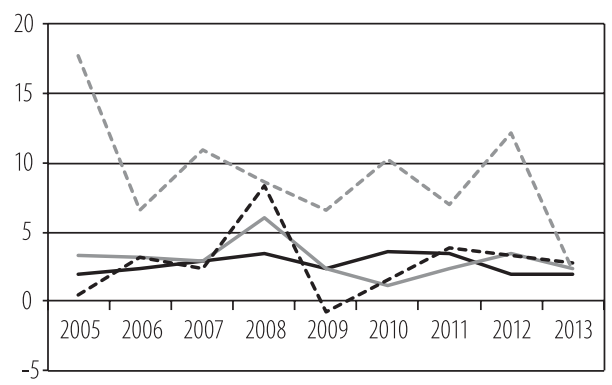

- ALBANIA Croatia -----Macedonia -----Serbia

Source: European Commission, National institutions. pre-crisis years, the global crisis they all had a sound GDP growth between 4-6\% annually (Figure 1). The impact of the crisis was mainly visible in 2009 when most of the countries registered GDP decline and thereafter in 2012 when GDP decline was much smaller. In 2013, Macedonia and Serbia registered a sound GDP recovery, while this was not the case with Croatia. Albania was the only country that did not have a GDP decline in the crisis period, but with a gradual and continuous GDP slowdown in recent years.

Inflation developments in the analysed SEE countries have also shown some similarities (Figure 2). In 2008, there was common upward pressure over inflation, mainly reflecting the world oil and food prices, which was offset in the following year. If we exclude these two years, generally, the inflation in most of the analysed SEE countries was on a moderate and relatively stable level during the crisis. Serbia is an exception considering that it is a country with higher inflation rates, reaching two-digit levels in some years and yet slowed down to the level similar to the other countries in 2013, mainly reflecting downward pressures from the world oil and food prices. 
Therefore, the environment for monetary policy implementation in the SEE region during the crisis period was marked by GDP slowdown and also by mainly moderate and stable inflation (with the exception of Serbia). In the pre-crisis period, the reference interest rates in the analysed SEE countries (Figure 3) were stable or declining, while at the beginning of the crisis, the central banks increased the interest rates, with the time horizons carrying by the country. Considering the strong credit expansion in these countries at the beginning of the crisis, the interest rates increase was probably motivated to slowdown lending, or maybe to stabilize inflation by influencing domestic drivers of inflation or in some cases to cope with the exchange rate pressures. However, considering a strong impact of the crisis on the real economy, further there was some downward adjustment of the interest rates, considering stable inflationary developments. In many of those countries, the reference interest rates reached the historical minimum in 2013-2014 (in Albania and Macedonia around 3\%).

However, the interest rate transmission channel had many shortcomings even before the crisis considering the structural changes and stage of development of the financial system in the transition economies that actually complicated even more during the crisis when the monetary transmission was generally impaired (due to global uncertainty). That was the main reason for the central banks to start to amend other monetary policy instruments or even to use non-standard alternative measures to transmit monetary policy signals to the real economy.

Figure 3: Reference interest rates (in \%)

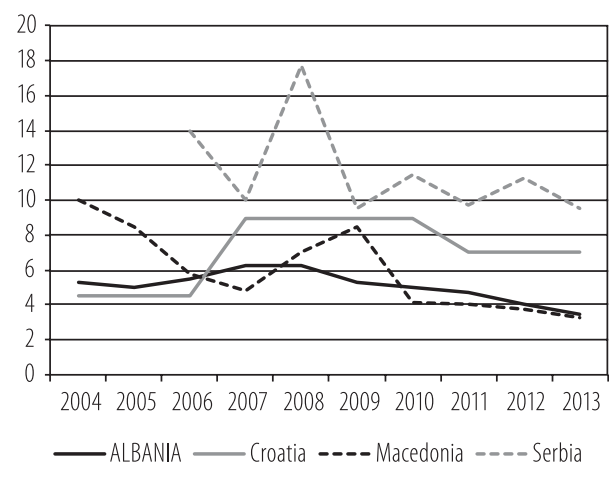

Source: National central banks.

Figure 4: Weighted average reserve requirement ratio (in \%)

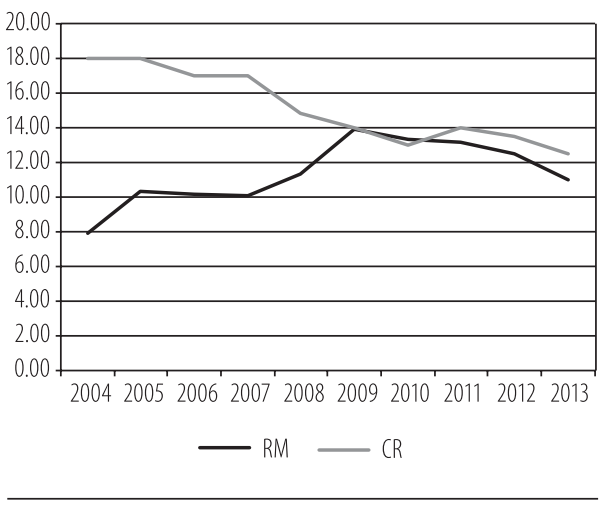

Source: National central banks. 
Some of the central banks in the SEE region (in Macedonia, Croatia) started with a gradual reduction of the average reserve requirement ratio (Figure 4) during the crisis period (and also to take other measures). In this way, they were mainly trying to support lending activity of the banks that significantly decelerated during the crisis period (in some countries - Croatia and Serbia, it went even to negative zone) and therefore to support the economic recovery. The intention of the central banks in the region to support the real economy was quite visible, however it requires further analysis.

Figure 5: Output gap

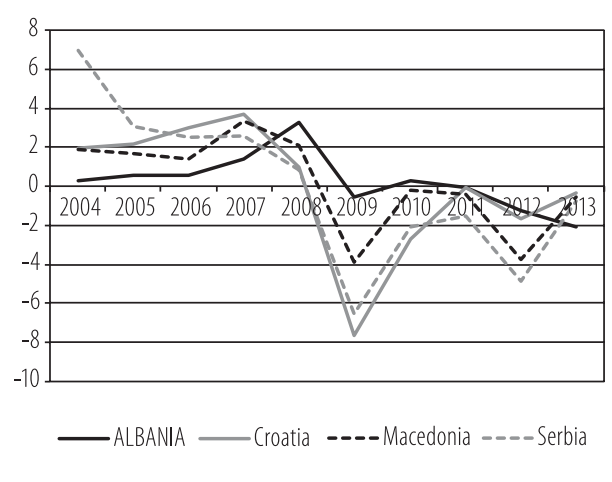

Source: Author's calculation.

Figure 6: Inflation gap

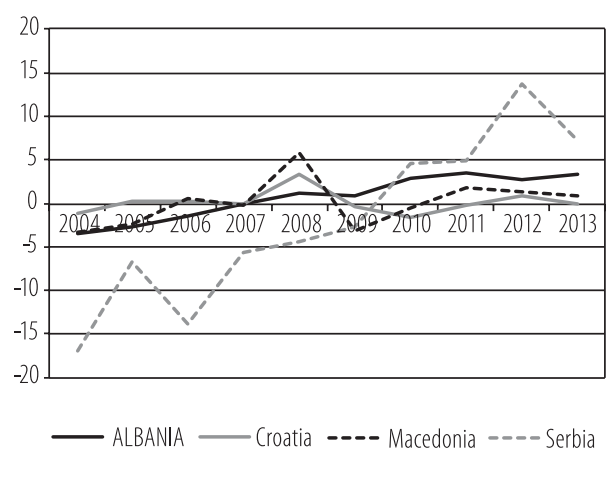

Source: Author's calculation.

\section{Analysis of the monetary policy objectives in SEE countries during the crisis}

The monetary policy in the SEE countries during the crisis was mainly accommodative, although it varied across the years in different countries. In this segment we will try to examine if the monetary policy stance was only influenced by the price stability objective, or the real output stabilization has been also taken into account. For this purpose, we looked into output and inflation gap developments in the analysed countries. Both gaps are calculated as differences to the Hodrick Prescott (HP) filtered trend for the overall analysed period (1995-2013).

When looking into output gap dynamics, one can notice that opposite to the pre-crisis positive output gap, during the crisis the output gap in all analyzed countries was negative (Figure 5). According the GDP performances, the negative output gap was largest in 2009, than in 2012. Regarding inflation gap dynamics (Figure 6), we must notice significantly different behavior 
in Serbia, when it was significantly negative prior the crisis (considering higher inflation previously and its gradual decline during transition period). Then it returned to positive gap, with some slowdown in 2013. The inflation gap in the other three countries, if we exclude the external shock in 2008 and following offset in 2009, was mainly stable at relatively low levels, pointing to the fact that inflation in these countries was not really a concern.

Furthermore, it is interesting to see the developments of the reference interest rates in line with the developments in output gap and inflation gap (Figure 7). Analysing by countries, it seems that monetary policy was taking care of output gap stabilization during the crisis in Albania and to some extent in Croatia, Macedonia and Serbia. In all cases, we assume that when the monetary policy was supporting output gap stabilization the inflation was at the level that was not of concern for the monetary policy or driven by the factors outside the influence of the monetary policy. Anyway, visual inspection of these developments will hardly give any clear-cut conclusions.

Figure 7: Reference interest rate, output gap and inflation gap by countries
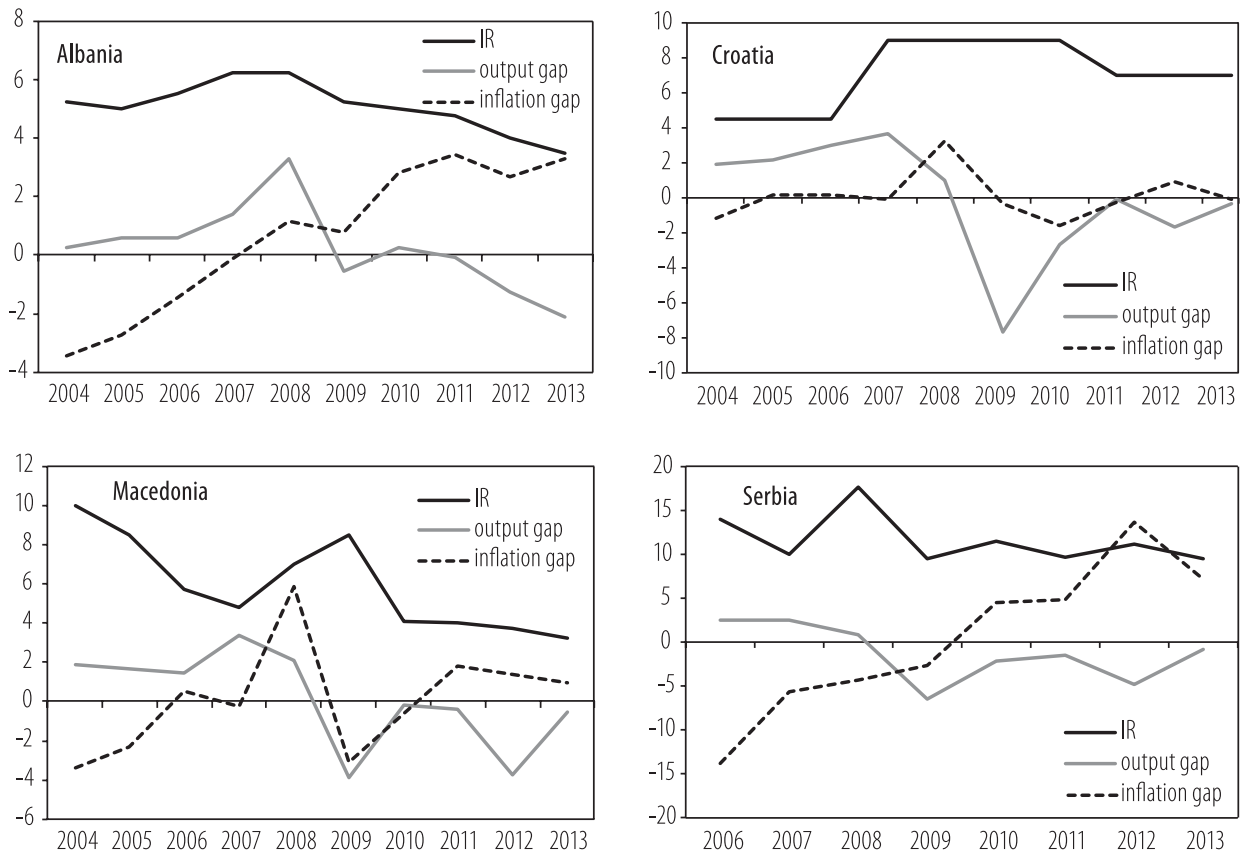

Source: National central banks and author's calculation. 
Figure 8: Standard deviation of the output gap, by countries

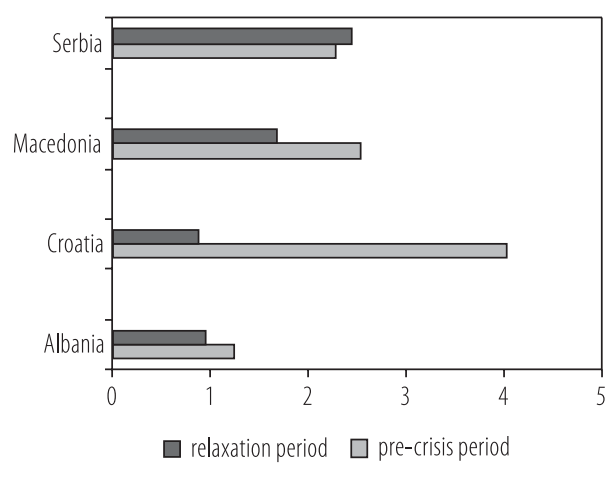

Source: Author's calculation.
Likewise, we look into variability measures in the pre-crisis and the relaxation period. The analysis of standard deviation of the output gap in sub-periods by the country confirms lower standard deviation during the relaxation period (Figure 8). Only in the case of Serbia there was a relatively stable standard deviation in the period of the monetary policy relaxation (the start of the relaxation period differs across the countries in line with monetary policy changes). This gives room to assume that, besides inflation stabilization, monetary policies in the SEE countries also influenced the output gap stabilization during the crisis. In

favour of this argument is also the relaxation in other instruments during the crisis period over the past years when the output gap was generally more stable.

In order to further analyse whether there is a clear relationship between policy rate and output gap, we created scatter plots for these two variables over longer time horizon and only for the period of monetary policy relaxation during the crisis (Figure 9). In the case of Albania, we found distinctive positive linear relationship for a longer time period and for the policy relaxation period, too. For Croatia, it is the opposite, with negative relationship between referent interest rate and output gap, although it seems that the negative slope is milder during the crisis period and monetary policy relaxation. This indicates that anyway during the crisis the stabilization of the output became more important than before, which additionally has been supported by the reduction of average reserve requirements ratio. In the Macedonian economy, from slightly inverse relationship the policy rate has shown a slight positive relationship to the output gap during the crisis, pointing to the efforts to take care of this variable during the crisis. However, in Serbia, this relationship moved from slightly positive to slightly negative during the crisis, indicating that it was difficult to take care of output stabilization during the crisis, probably due to fluctuations in inflation rate and/or exchange rate. For illustration, the average inflation rate in Serbia in 2012 was around $12 \%$ and it significantly dropped to around $2 \%$ in 2013. In the period 2009 - 2013, the Serbian dinar depreciated against the Euro by $7 \%$, on average (it appreciated slightly only in 2011). 
Figure 9: Scatter plots of output gap (axis $\mathrm{x}$ ) and interest rates (axis $\mathrm{y}$ ), y countries (\%) (left-hand side Figure: overall analysed period, right-hand side Figure: monetary policy relaxation period)
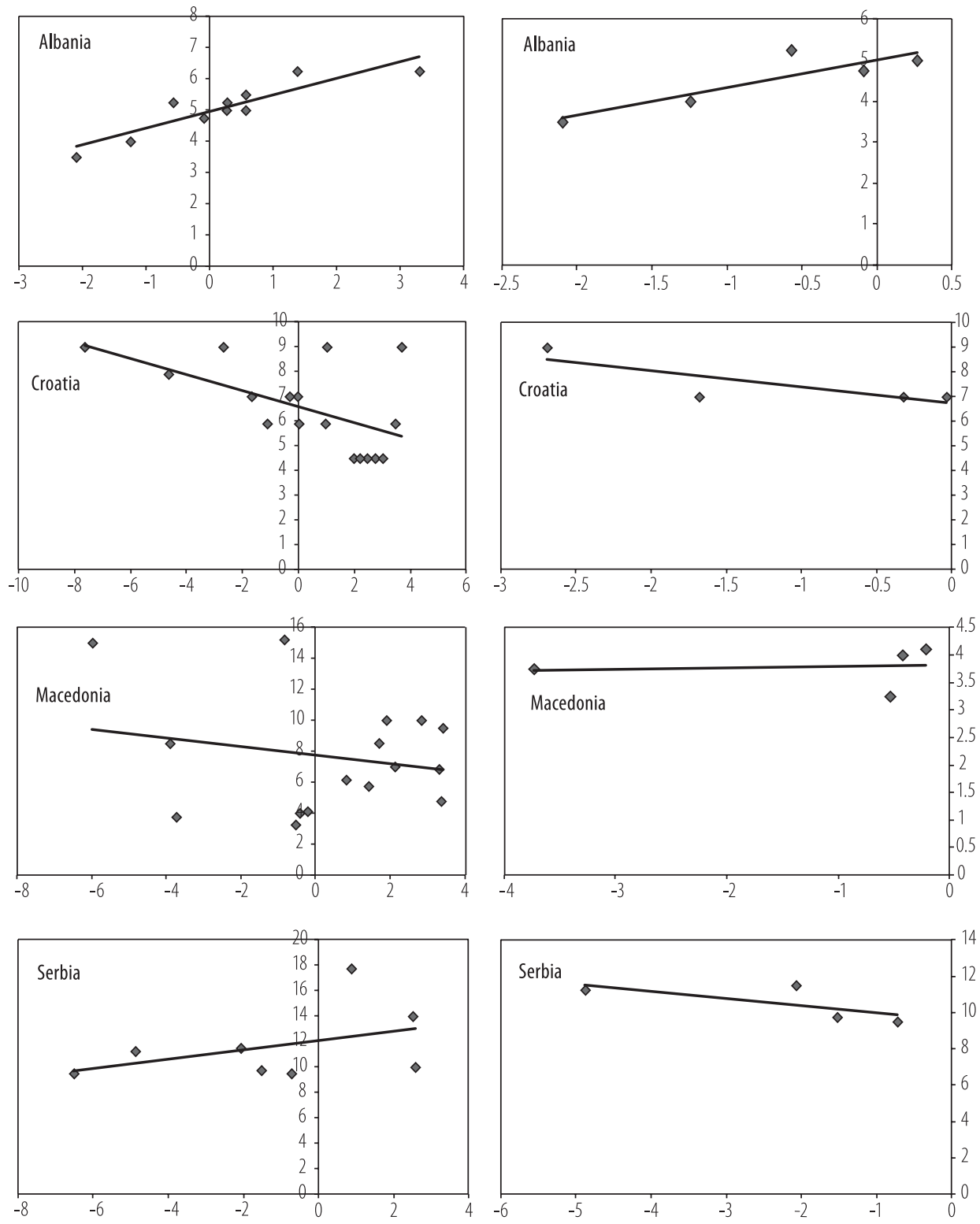

Source: Author's calculation. 
It is important to note that this is a rather simple analysis with the aim to get some insights whether the list of objectives of the central banks in the analysed SEE region changed during the crisis towards output stabilization. A relatively short period of analysis is one of the main shortcomings of the analysis since we are exploring something that appeared recently and is still ongoing. Therefore, we are limited in applying more sophisticated empirical approach to explore this issue in more detail. In addition, a more profound calculation of the output gap for the analysed countries could be also a challenge for a further analysis in this area.

Therefore, there are many possibilities for further and deeper examination of this subject in the future. However, our findings are already pointing to the fact that the central banks in the SEE countries paid attention to the output stabilization, specifically during the crisis period (some of them even before) and that was presumably enabled by controllable inflation developments. Serbia is the only country from the analysed group with higher inflation in recent history, which faced inflation fluctuations during the crisis that, together with the exchange rate fluctuations, were probably obstacles for the monetary policy to take more care of the output stabilization during the crisis. In favour of the arguments that monetary policy in the SEE countries supported economic stabilization during the crisis were also other measures taken by the central banks, besides interest rate reduction. In this view, we mentioned the changes in reserve requirements in two countries, but many other monetary and prudential measures have been taken by the central banks aiming to support the economic recovery.

\section{Conclusion}

Central bankers worldwide experienced many challenges during the crisis regarding the types of implemented measures and instruments, the scope of interventions, required flexibility, even regarding the policy objectives. The issue of the monetary policy objectives is not a new one, but definitely is gaining in importance nowadays. There are many contributions in the literature indicating that besides price stability, monetary policy must take care of output stability as well. This is something that was practiced during the crisis although in different ways in developed and emerging economies. Central banks in developed economies under the zero lower bound took additional measures to support output. Central banks in emerging economies, including the SEE countries, were gradually reducing the interest rate and also took specific measures aimed at supporting the recovery. 
In order to check whether the output stabilization was included on the list of objectives of the SEE central banks, we analysed the developments of the policy interest rates and output gap, variability of the output gap during the monetary policy relaxation during the crisis, and we examined the linear relationship of the policy rate and output gap. Our findings are already pointing to the fact that the SEE central banks paid attention to the output stabilization, specifically during the crisis period (some of them even before) and that was presumably enabled by controllable inflation developments. Serbia is the only country from the analysed group with higher inflation episodes in recent history and which faced inflation fluctuations during the crisis that were probably an obstacle for the monetary policy to take more care of the output stabilization during the crisis. However, this analysis gave only some insights regarding the list of the objectives of the SEE central banks during the crisis, while more profound conclusions are limited and they will be possible once longer period under these settings as well as more precise calculation of the output gap have been available.

In favour of the arguments that monetary policy in the selected SEE countries supported economic stabilization during the crisis are also other measures taken by the central banks, besides interest rate reduction. In this view, we mentioned the changes in reserve requirements in some of the analysed countries, but also many other monetary and prudential measures were taken by the SEE central banks with a view to supporting the economic recovery. 


\section{References:}

1. Bank of Albania, www.bankofalbania.org;

2. Carney M. (2009), Some considerations on using monetary policy to stabilize economic activity, Governor of the Bank of Canada, Symposium at Jackson Hole, Wyoming, August 2009;

3. European Commission, EU Candidate \& potential candidate countries' Economic Quarterly (CCEQ), different editions;

4. National Bank of Croatia, www.hnb.hr;

5. National Bank of the Republic of Macedonia, www.nbrm.mk;

6. National Bank of Serbia, www.nbs.rs;

7. Svensson L. (2003), Monetary policy and real stabilization, NBER Working Paper No.9486, February 2003;

8. Svensson L. (2009), Evaluating monetary policy, NBER Working Paper No.15385, September 2009;

9. FED (2014), Statement on Longer-Run Goals and Monetary Policy Strategy, January 28, 2014;

10. Walsh C. (2009), Using monetary policy to stabilize economic activity, University of California, Santa Cruz, August 2009. 